\title{
MOVING, MAKING AND ATMOSPHERE: ROUTINES OF HOME AS SITES FOR MUNDANE IMPROVISATION
}

Sarah Pink (RMIT University, Australia) and Kerstin Leder Mackley (Loughborough University, UK)

\begin{abstract}
In this article we examine how everyday atmospheres of home are made, maintained, and improvised through habitual routines of movement, and the implications of this for codesign for energy demand reduction. Drawing on our ethnography of how people experienced and constituted a sensory aesthetic of home we analyse the example of lighting use in night time routines. We propose seeing these routines as sites of the possible, where everyday making might be engaged for co-design. Thus suggesting refocusing ethnographic design research beyond what people do in their homes, towards how they move through and make the atmospheres of their homes.
\end{abstract}

Key words: movement; atmosphere; home; improvisation; light; ethnography.

\section{Introduction}

There is an extensive literature about everyday life in the home, emerging from anthropology, human geography, sociology, design, and human-computer interaction (HCI) research. Yet while the concept of movement has often been used to understand the everyday, its 'flow' and its ongoingness (Highmore 2002, Thrift 2008), movement is infrequently engaged to understand either how people live in their homes (but see Pink 2012), how they experience and make the atmospheres of their homes (Bille 2014) or how change and future-making might be designed in homes.

Social science theory and concepts are increasingly being engaged for design practice in homes in novel ways (e.g. Kuijer et al 2013, Pink et al 2013), in this article we advance this relationship by asking how movement might be used as an antytical research and design category. To explore this we draw on our research about how skilled knowing and improvisation are engaged within the night time routines of people who 
participated in our sensory ethnography of everyday energy and digital media use in 20 UK households. In doing so we examine how they moved through their homes at night time, using lighting in tacit, normally unspoken about ways to make, maintain and improvise atmospheres of home. Night time routines of movement, are indeed an ideal example through which to explore these questions. We initially researched night time routines because we believed that they would be important transition moments for energy use. However they exceeded this promise in that by revealing aspects of the routine and improvisory activity that is integral to everyday living but almost never spoken about or researched, they emerged as key habitual and tacitly known moments in everyday life. As transition routines they are routines of making, maintaining, experiencing and knowing the night time home. They show us how through lighting and switching (on and off) activities our participants made what has been called an affective atmosphere (eg Anderson 2009) of the night time home. The study of these routines shows how improvisation becomes embedded in everyday habitual movement through the home and suggests that therefore such moments/movements are potential sites for generating codesign processes, to which improvisation is also core. Thus, we advance the question of how to co-design for change in the home by suggesting a focus not on what people do in their homes, but by concentrating on their potential as makers - that is on how they improvise as they move through their homes.

In what follows we first outline our project and approach. We then unpack the three themes that we critically engage with to develop our argument: making and atmospheres; home and routines of movement; and light and darkness. Bringing these together we suggest how we might understand home night time routines as a sites for improvisory making. We then connect our discussion to recent work in co-design and design anthropology to suggest these routes/routines as potential sites for change-making.

\section{Paths of research: the context for our project}

The examples we discuss in this article are from the first stage of a sensory ethnography study undertaken within the large LEEDR interdisciplinary research and design project. The project involves research with twenty owner-occupied family households living in the middle of England who have a range of interests and levels of environmental 
consciousness. They were recruited through local advertising and snowballing and all participated in a variety of qualitative ethnographic and design research exercises and longitudinal energy monitoring as part of the wider project. The first stage of our ethnographic strand focused on understanding how energy was consumed as part of the process of the ongoingness of the everyday constitution and perception of home as a sensory environment (Pink 2004) and the practical activities that participants engaged in to make and maintain their homes. During the research process we used the working concept of seeing this as a process of making the 'sensory aesthetic of home'. With the participants we discussed this in terms of how they made their homes 'feel right', keeping this open to both affective and embodied sensory ways of feeling. In this article we begin to connect this to theoretical literatures on atmosphere, as explained below. In a practical sense, ethnographically we explored these experiences and environments of home with participants using a collaborative video tour method, which we discuss in detail elsewhere (Pink and Leder Mackley 2012). Here we note this method was intentionally designed to explore the sensory dimensions of their homes (both in terms of the qualities and affordances of home as an environment and in terms of human perception) and the tacit ways of knowing and practical skills participants used to perceive and make home. The tours were led by participants but guided by our agenda. As part of this research encounter participants were asked to re-enact and reflect on their everyday going to bed routines, which gave us an opportunity to explore with them the ways in which they knew and made their homes as they retraced their habitual steps and moves through the home at night.

While the examples discussed here offer some preliminary ethnographic insights into how lighting, locking, media, pets and movement become intertwined, we stress that our aims in this article are primarily methodological and theoretical. We draw on selected research encounters in which we explored with participants their routes through their homes when they go to bed at night. We focus on uses of lighting specifically because for participants across our sample these were intrinsically linked to how they navigated, experienced and managed the home; in short, to how they negotiated the sensory aesthetic that made home and in combination with locking and checking activities made them feel safe. As we illustrate, despite (as well as because of) their idiosyncrasies, the 
examples presented here can be seen as representative of processes that were evident in the wider sample. They were chosen because they best illustrate both the differences and similarities that made up selected routines.

The sensory ethnography methodology we engaged departed from the observational approach of classic ethnographic practice 'to re-think both established and new participatory and collaborative ethnographic research techniques in terms of sensory perception, categories, meanings and values, ways of knowing and practices' (Pink 2009, 10). Our approach makes extensive use of video, to record participants as they move through their homes with us. This enables us to take an experiential approach to studying routines. Our method, rooted in the 'deep reflexivity' (MacDougall 1998) of visual anthropology practice, takes as its starting point the video-mediated shared encounter between participant and researcher. We interpret the researcher's and co-researcher's reviewing of the video recordings as a process of embodied sensory learning, whereby movement forward in knowing and being is still ongoing (see Pink 2009, Pink and Leder Mackley 2012). Ingold emphasizes how human experience, ways of knowing and learning are on-going, and incremental; they happen as we move through and make environments, that is, they are integral to human activity in the world. As our participants showed us how they navigated their night time homes we came to understand how they used lighting and locking to make and know theses everyday routes and environments.

Before, in the next sections, outlining the concepts through which we understand our research, we next present a narrative from our research in order to offer a sense of how our participants showed us their bed time routes.

By the time Alan gets home from his night shift at about 12.45 in the morning, the rest of the family is normally in bed. The last person to go up will have used the wooden stick kept by the TV and associated appliances to reach behind to the wall socket and switch them off, and thus avoid leaving them on standby all night.

With the household sleeping and in darkness, Alan goes in 'through the back way' by first entering the property through the electronic garage door at the front of the house. As the door slides up, a powerful light on the garage ceiling comes on automatically. It illuminates the area inside long enough for the door to return to its closed position and 
for Alan to go out through the back of the garage into the back garden where the sensor spotlight facing him lights up and guides him to the conservatory door. He goes in and, using the borrowed light of the spotlight, takes off his coat and shoes before going into the main house through the kitchen door. The spotlight goes off, and Alan has by now switched on the section of under-cupboard lighting in the kitchen next to the back door. This illuminates the kitchen surfaces along the part of the wall that connects with the internal door out of the kitchen through into the dining and living rooms. Switching on the under-cupboard lighting is habitual for Alan, not only as he comes home in the dark, but because he and his family prefer the cosier atmosphere it creates in the kitchen as opposed to the brighter overhead lighting. They usually light the kitchen in this way, with the addition of the oven light when using the extractor fan. Alan plugs in his mobile phone in to charge, in a socket on the illuminated kitchen surface. Then, following the light as it seeps through to the dining and living areas, he walks a well-practiced route to the doorway leading into the front hallway. There he switches on the downstairs ceiling light before re-crossing the unlit living and dining rooms to turn off the kitchen undercupboard lighting. Returning to the hallway, he climbs the stairs surely and firmly knowing their spacing with his body, and with the light on from below, and, he told us 'then the landing light's on' adding that 'when I get up stairs ... obviously I've turned everything off down stairs'. Borrowing the light from the landing he crosses the bedroom he shares with his wife to the en-suite (both rooms are an extension to the house, built over the garage) where he puts on the light before retracing his steps to switch off the landing light. The four children - two school age and two young adults - will not wake up as their bedroom doors are closed or pulled to. Following the remaining light, Alan returns to the en-suite. When he comes out, enough light still flows into the bedroom to enable him to get changed by the bed but maintains the room sufficiently dark for his wife not to be woken up. He finally switches off the en-suite light and takes a few steps across the darkened bedroom to go to bed.

Alan's route through his night time home was a well-practiced, habitual activity, a way of moving that was performed almost every 24 hours, normally not described or recounted, but nevertheless known and performed as part of a way of knowing in an environment 
with a certainty that enabled him to enact and explain it to us with precision. Indeed we were interested in the things that our participants knew 'in their bodies' because they 'felt' right, but that they did not necessarily (ever need to) talk about. Alan re-enacted this route for us, creating an abstracted and generalised version, which was simultaneously informed by his embodied and sensory memories and knowing about what he normally did and what felt 'right'. As we discuss elsewhere such re-enactments are collaborative memory-work research encounters, offering participants and researchers ways to access, recall and show the physicality, materiality and sensoriality experiential domains of everyday life that are normally unspoken (about) and unshown (Pink and Leder Mackely 2014). We have (unusually) written the account in the present tense. This is not intended to fix the narrative in an abstracting and generalising 'ethnographic present' but rather to more loyally represent the way our participant set his generalisations in the present of the moment when we did the ethnography.

While we knew from our earlier conversations that Alan was both keen to save energy generally and not to wake up his family, when Sarah asked about these in relation to this route he told us '... it's just turning the lights on I need to get to where I need to go'. Yet in interpreting his point, we need to ask what role light played in this process: why for instance did Alan who knew his home, which he had lived in for a number of years and much of which he had crafted with his own hands as a sensory environment, need to put on the lights to navigate it and move through it at night? And why did he not fully light the rooms he moved through, but instead borrow lighting from other rooms or

outdoors? This led us to focus on the improvisory ways in which our participants showed us how they used light as they moved through the home in their re-enactments, to ask ourselves how light and darkness were used to enable forms of knowing, making and maintaining of the atmosphere of the night time home.

\section{Making and atmospheres}

The concepts of making and atmosphere are significant in current debates both separately and in relation to each other. Both concepts have at their core the problematic of the relationship between people, things and environments, and as we will return to later in this article, can be understood as involving movement. Here we are interested in both 
how atmospheres are defined and how they emerge and Böhme's foundational essay 'Atmosphere as the Fundamental Concept of a New Aesthetics' (1993) offers a useful starting point. Böhme argues that it is necessary to understand atmospheres not as separate from things and people, they are not 'free floating' $(1993,122)$. Thus atmosphere 'is the reality of the perceived as the sphere of its presence and the reality of the perceiver, insofar as in sensing the atmosphere s/he is bodily present in a certain way' $(1993,122)$. Of particular interest for the discussion here is that Böhme applies this understanding to the idea of making atmospheres. He develops through the example of the aesthetic work of crafting arguing that 'Aesthetic work consists of giving things, environments or also the human being such properties from which something can proceed. That is, it is a question of "making" atmospheres through work on an object' and that 'knowledge about the production of atmospheres is very seldom explicit' (Böhme $(1993,123)$. Böhme urges that this principle should be applied the 'aesthetics of everyday life' $(1993,125)$ as much as to artistic or creative work. In a later essay he explains further that the 'making' of atmospheres through the idea that making 'does not really consist in producing a thing, but in making possible the appearance of a phenomenon by establishing conditions' $(2013,4)$.

Human geographers have developed this concept of atmosphere further in the context of seeking to understand the production of affective atmospheres with a particular focus on the social, embodied and affective aspects of the production of atmosphere. Therefore Ben Anderson builds on Böhme's work to discuss how atmospheres 'proceed from' rather than being 'created by bodies' and are therefore not reducible to bodies. Rather, he suggests that 'The singular affective qualities that are atmospheres - homely serene, erotic and so on - exceed that from which they emanate'. He sees atmospheres as 'a kind of indeterminate affective "excess" through which intensive space-times can be created' $(2009,80$, italics added). In human geography a focus on the sociality of affective atmospheres has developed (eg Anderson 2009, Bissell xxxx) and as we discuss further below the collective making of atmosphere has also become of interest in the anthropology of home (Bille 2014). However while we are interested in the affective qualities of atmosphere-making, our own ethnography has also focused on how atmospheres are experienced and made at some of the most hidden and mundane 
moments of our participants' everyday lives, where sociality might mean not waking others up rather than explicitly sharing affective atmospheres with them. We return to this later. First however we consider in more detail the concept of making and its implications for understanding how atmospheres might be made.

Ingold has proposed that making should not be seen as a process of producing a preconceived artefact but as a 'process of growth' (original italics) whereby the maker is 'a participant in amongst a world of active materials' $(2013,21)$. Just as Böhme has called for the making of atmospheres to be investigated as part of everyday life and as such beyond the work of creative practitioners, likewise Ingold proposes that making is not just the domain of professional designers but also of part of the everyday activity of people who might be considered 'designers and makers in their own right' (Ingold 2012, 32). Indeed in both approaches it is not the product or finished design that is so much of interest, but the 'making possible' (Böhme 2013) in that Ingold subsequently asks how we might 'design for improvisation' (original italics), where 'the improvisory interventions of practitioners present an opportunity rather than threat' (Ingold 2012, 32). Making therefore can be understood as part of the everyday activity of householders, who engage their own skilled ways of knowing and improvisory tendencies in the everyday tasks of home. Part of this involves indeed the making of affective atmospheres of home, and following Ingold we might understand the makers of such atmospheres of home as doing so from within a 'world of active materials' $(2013,12)$, that is as inhabitants and part of the environments of home they are constituting.

Therefore we can understand the atmospheres as emergent from processes of making. That is from the encounters between people, materials and other elements of the environments of which they are part (eg air, light, warmth, scents). Atmospheres are not as such products but they are produced or emergent ongoingly as people improvise their ways through the world. In the next section we examine how a focus on home and routines of movement adds to this understanding.

\section{Homes and routines of movement}

In human geography and anthropology the home has been discussed as for instance, an ambiguous site for everyday politics or oppression (eg Blunt and Dowling 2007, Brickell 
2012) or consumption (see Casey and Martens 2007), as well as in terms of its materiality (eg Miller 2001) and sensoriality (Pink 2004). It is however infrequently discussed, even within the context of these existing debates, as a site for/of movement or making (exceptions include Pink 2012, Ferguson 2010). Taking a cue from Ingold's proposal that 'The path, not the place, is the primary condition of being, or rather of becoming' (Ingold 2008,1808 ), we have focused on movement through the home. Our interest is in determining movement as a site of making and thus as potentially a site for co-design and therefore our aim is to establish how movement is implicated in the ongoing experience and production/making of the affective atmospheres of home. A particularly pertinent example of the utility of focusing on movement through homes is shown in the work of Harry Ferguson who focuses on the movement of social workers when undertaking home visits. To consider how social workers experience the atmosphere of other people's homes, Ferguson has emphasised Urry's definition of 'atmosphere' as 'being "in the relationship of people and objects. It is something sensed often through movement and experienced in a tactile kind of way" (Urry, 2007, p. 73)' (Ferguson 2010, 1102). We advance this proposition to consider how more everyday forms of movement by people in their own homes, are implicated in routine ways of making atmospheres of home.

There is a vast and long standing social science and humanities literature around routines, and a growing interest in this area, in the context of applied research (Martens et al 2014). Much research into routines focuses on mundane and everyday activity, of particular interest here in ethnological scholarship by connecting to morning routines (Ehn and Lofgren 2009) and movement in commuting (O’Dell 2009). The study of routine is also in more strictly disciplinary traditions inflected with discipline-specific theory. Therefore sociologists have tended towards researching and understanding routines through social practice theory (see Halkier et al 2011, Martens 2012).

Geographers have approached routines and rhythms through time-geography (see Edensor 2010), although as discussed below a critical processual approach to geography (Merriman 2011) contests the focus on time-space by suggesting that we need new ways of 'expressing how we think and feel our worlds and understand events' (2011, 24). For the purposes of our discussion here, following our interest in the relationship between routine and movement, we focus specifically on the idea of routine as route. As Ehn and 
Lofgren, point out 'The word 'routine' is actually the diminutive of route, the making of small paths in everyday lives' $(2009,100)$. Pulling out the similarities between routines and paths they note how both are followed unconsciously, but that once asked, people are able to discuss them in depth $(2009,100)$. Ehn and Lofgren's own work on morning routines is significant in showing how what might appear a mundane routine activity is in fact meaningfully bound up with the politics and affect of everyday life, how routines might become ruptured, and the transformative impact of this.

Our interest in transformation is different in that we are concerned with how it might be initiated through mundane improvisation as routines are lived and experienced, as part of the processuality and environments and atmospheres of the everyday. To conceptualise this we need a way of thinking about the home that accommodates the routines/routes of movement that are made through it. Ingold's understanding of the environment as an unbounded 'meshwork' or 'entanglement' of lines $(2008,2011)$, constituted though movement, enables us to both understand the processual state of place, and situate movement both as an experiential and constituting element of it. As Ingold puts it:

Places are formed through movement, when a movement along turns into a movement around ... Such movement around is place-binding, but it is not placebound. There could be no places were it not for the comings and goings of human beings and other organisms to and from them, from and to places elsewhere. Instead of saying that living beings exist in places, I would thus prefer to say that places occur along the life paths of beings. (Ingold 2008, 1808)

With such 'unbounded' (Ingold 2008) ecologies of place, unique routines and improvisory practices are constituted, lived out and contribute to the making of everyday environments and can therefore be thought of as productive of affective atmospheres of home. Routines therefore are not simply performed in homes, but are part of the ongoing processes through which a home, its atmosphere and the living of everyday domestic life are constituted and experienced. For example, Alan's route or path through his home, described above, might as such be understood as part of the ongoingness of how the 
continually changing and partially invisible (but sensed and known) landscape and atmosphere of home is adjusted. The home as an ongoingly changing place is thus created in part because Alan is moving through sensing, using light, and switching on and off. Yet it is also constituted through Alan's unique routines, as he engages lighting in ways that he has developed, sensed and come to know as a route through the night time home. Routines of home might therefore, be understood as routes or pathways of movement through the home. They also become processes through which people, things and environments come together to make atmospheres.

Routines of movement are also moments where atmospheres of home are known and experienced - in tandem with their making. The idea that human perception happens as we move through and as part of an environment (see Ingold 2000, 2011) and thus the proposal that knowing is something that happens in movement (e.g. Harris 2007) has underpinned our sensory ethnography methodology (Pink 2009) and our understanding of how people experience their homes. Appreciations of cognition as something that happens not 'in our heads' but following the work of the ecological psychologist James Gibson, as part of our ongoing engagements with and movement in the environment inform both Ingold's work (e.g. 2000) and the work of scholars across different disciplines who likewise investigate how we know and learn (e.g. Stafford 2006). Following these lines of thought, the everyday routines that we discuss involve embodied, tacit ways of knowing and sensing. They are perceptual experiences that are not necessarily (usually) ever shared or communicated about verbally, or divided up into the sensory categories of vision, sound, smell, touch and taste (see Pink 2009) we see 'Vision, hearing and the rest ... [as] ... aspects of action - ways of attentively going forth in the world; they are not filters in the conversion of external physical stimuli into internal mental representations' (Ingold 2011, 325).

By bringing together movement with perception as such we can focus on the question of not only how routines of movement make atmospheres, but how they are integral to the ways we perceive them. Lighting, as we argue is experiential and relational, as our research has shown, it is not simply for visual contemplation but part of the way the atmosphere of home 'feels'. In the next section we examine recent discussions of lighting to locate it more firmly as a participant in the ways that 
atmospheres are made.

\section{Approaching lighting and darkness}

One of the key themes to emerge from our ethnography of routines of movement related to the ways in which lighting was used during transitional moments in the home. Therefore before discussing our ethnographic findings in more detail we bring together the discussion above with recent literature about light and lighting in anthropology and human geography, some of which has emerged in relation to theoretical and empirical interests in the concept of atmosphere.

Ingold has argued that 'Only a living body can know, and if knowledge is embodied, this is only because the body, in turn, is enwinded (Ingold 2007b: S32 ). Or in the words of environmental philosopher David Macauley, "with our heads immersed in the thickness of the atmosphere or our lungs and limbs engaged with the surrounding winds, we breathe, think and dream in the regions of the air" (2005: 307)' (Ingold 2010, S316) (original italics). Light is indeed part of such atmospheres and we are interested in how light is enmeshed with the sensory and material affordances of the home, its objects, electricity, technologies and air. We therefore understand light as part of the environment rather than something that is separate from it and cast onto it. Ingold argues that rather than being 'a phenomenon of the physical world ... or of the interior mind' light is 'an experience' and 'For sighted persons, it is the experience of inhabiting the world of the visible, and its qualities - of brilliance and shade, tint and colour, and saturation - are variations on this experience' $(2011,128)$.

This leads us to ask how then we see with light. Seeing, Ingold argues, is thus based in the experience of light, rather than light being something we can see. Indeed according to Ingold it is not only seeing and light that we understand as part of rather than separate from the environment. Instead, 'The sight, hearing and touch of things are grounded in the experience, respectively, of light, sound and feeling'. According to this approach we are not only 'observers, picking our way around the objects lying about on the ground of a ready-formed world, we must imagine ourselves in first place as participants in a "world-in-formation"' $(2011,129)$. Therefore, as the geographer Tim Edensor proposes 'We see both with and in light and move through illuminated space, 
making engagement with light a deeply embodied experience' (2012,1107). Turning back to the example of Alan's night time home described above, we can see how Alan engaged light not simply as a direct illumination on a room-by-room basis, but rather he sensed light as flowing between rooms, and through windows. Lighting from one room was borrowed for another, to assist him in tasks and accompany him on his way. He did not always use light to stay still or to contemplate a visible materiality in a particular location, but as part of the process and rhythm of moving through his home. Here light is experienced, rather than contemplated, and indeed approaches that treat light as experiential rather than an object, are becoming increasingly important. Edensor has (although writing in a different context, about urban darkness) argued that 'rather than considering the nocturnal and diurnal, and light and darkness, to be opposing states, ... it is more productive and realistic to develop a relational understanding of these conditions' $(2013,14)$. Edensor has also emphasized the transformative potential of light, in that it 'alters the perception of the colour and shape of space and is both a discrete material object comprising an assemblage of elements and a property that extends across space' (2012, 1107). Light, then plays a role in the making and experience of atmospheres, equally for the night time illuminations that Edensor writes of and for the night time home.

Light is however not only experienced as a form of sensory perception, but also as Mikel Bille shows, through affective atmospheres. Bille, uses his ethnographic research into how lighting is used in Danish homes to explore how light is used in the generation of affective 'cosy' atmospheres corresponding with the Danish concept of hygge, and a sense of community (Bille 2014). In tune with earlier work where Bille and Sørensen have proposed 'an anthropology of luminosity; an examination of how light is used socially to illuminate places, people and things, and hence affect the experiences and materiality of these, in culturally specific ways' $(2007,265)$, Bille is interested in the ways that light is 'used to shape emotions in and of the home' $(2014,2)$ (original italics) and part of 'partaking in a neighbourhood community' $(2014,3)$. He argues that 'the interplay between intensities of light, darkness, glow and shadows becomes an element of the continuous creation of atmospheres through the informants' lighting practices' (2014, 5). Indeed for Bille, light plays an important role in the making of atmosphere in that 'it 
is continually used to create physical orientation in a room and to mentally attune to the situation and is a dynamic part of shaping the intensity of the atmospheres into what they are or should be' $(2014,7)$.

In the next section we discuss another example from our sensory ethnography research in order to bring together these insights that show us how light as experienced, sensorially and affectively becomes part of the atmosphere of home, with the themes of making, improvisation, movement and knowing introduced above.

\section{Making, moving, lighting}

In the preceding sections we have brought together, respectively the concepts of: making and atmospheres; moving and home; and lighting and perception. We have suggested that atmospheres of home should be understood as emergent from the improvisory everyday processes of making that householders go about as they move through their homes undertaking habitual, often unspoken about routines. We have then focused in on lighting and as an example of one of the technologies and experiential qualities through which atmospheres of home might be made and perceived. We now explore, through a second account from our sensory ethnography of night time routines, more specifically how a night time home is made through switching and lighting activities.

By about 11.30 at night Lee, who is an academic, is usually sitting on the sofa, reading in front of the $T V$, with the cat by his side and the living room lit by a standing lamp close to where he is sitting. The curtains are closed already. Lee is normally the last to go to bed. Before going up, he picks up the cat and, as he leaves the room, switches on the main living room ceiling light at the wall, telling Kerstin, who is video recording his enactment of the bed time routine, that 'there's a reason for that'. Partly, Lee needs the main light to later do his final 'sweep' through the living room and shut down the living room media devices; he subsequently told us by e-mail that the ceiling light also helps him to locate the switch on the standing lamp and saves him from navigating his way through a dark room. Lee carries the cat in his arms through the long kitchen, switching on the kitchen light on the way, and puts the cat out of the back door, shutting her out with the door locked up for the night. On his way back through the kitchen he checks that the kitchen 
$T V$ is switched off at the socket, goes to the toilet, which is just off the kitchen, so as not to make noise upstairs, turns off the kitchen light, and then returns to the living room where the main light is still on. In the living room, now with no cat to contend with, he turns off the standing lamp, switches the TV off at the socket and turns the Sky box onto standby (he points out that he cannot switch off the Sky box completely as the system would reboot). As with Alan's household, switching off before going upstairs is a key element of the ways most of our participants engage with the home as they move through it at bed time. Participants variously explained to us if they turned TVs off at the wall or to standby, how they did this (with a stick, with a remote control device that turns all off, or with their hands) or if they did not (because this would disturb the system somehow, or because they simply don 't). Yet the contingencies of ' why' the domestic landscape of energy consumption is altered by switching the TV off, are not the only issue, the other is 'how'. Lee's is a case in point: the kitchen and living room TV are switched off at the wall, the Sky box and, as we find out later, the bedroom TV are put to standby. But the cat is also involved in this process, because his route through the home involves his picking up the cat, changing the living room lighting, lighting the kitchen and downstairs toilet, and then returning to the living room to finish turning off appliances related to the $T V$.

Lee then noted how at this point, 'I make sure I've got my phone on me'something else that we would realise was important later - and he turns out the living room light. He switches off the ceiling light via a switch by the door, now leaving the dark living room behind him. The hallway light, which would have been put on when the cat was taken out, is now changed for the landing light upstairs. Lee follows the light up, onto the landing where all the doors leading to the bedrooms would be shut. In the bathroom with the light on he brushes his teeth and washes his face before coming to another of the innovative moments in his routine; as he described while he showed Kerstin through the route he would take 'Then, this is the clever bit, because Caroline doesn't like to be disturbed when she is asleep', he lights up his iPhone using its glow to guide him from the now dark landing into the bedroom, where he connects the iPhone into its white charging cable and activates the power supply. He then gets into bed, with the TV opposite on standby as the socket is out of reach. 
Like Alan, Lee borrowed lighting from one room to light another, he also used lighting for more than illumination - the living room light was switched on as he left the room to take the cat out. It was part of his route of return on his way upstairs. Thus for Lee, lighting was about sensing the home, it involved creating a route in a way that was habitual and practical, but, practical in the sense that lights aided remembering and prevent unnecessary back-tracking as much as being solely for visual contemplation. Lee also appropriated his mobile phone as a light and, like Alan, plugged it in to charge overnight. Both Lee and Alan thus used light in several skilled ways at night time, they engaged its flows as it spills over from one room to another, they regulated its intensity through unique improvisations, allowing it to seep through doorways or to emanate from the phone. More broadly participants in our project likewise closed out or opened out to flows of light. For example doors might be shut to prevent light from the street seeping or, in the case of one participant streetlights were used to sense his way through the home, when navigating his way through semi-lit hallway from stairs to kitchen during an early morning start to the day. Moreover, lighting was used by participants across the sample to signal presence for security purposes (for instance to deter burglars), and as affective symbol; one woman participant described leaving on the light in the hallway for family members to return at night as both a health and safety measure and a way of letting relatives know that they were being thought of.

These uses, appropriations and improvisations with light are produced through participants' sensory embodied and affective engagements with their environments; they entangled with ways people navigate the habitual routes they take through their homes every night, but they are not commonly discussed or articulated verbally. In moving through their homes in such ways participants were at once experiencing and making a specific sensory and affective atmosphere, and accomplishing a set of tasks, by switching off and on energy sources and thus creating part of the changing landscape of energy flows through the home. Yet the ways they do this are idiosyncratic and complex. While we would agree that there are identifiable practices of switching off the TV and using electric lighting to get upstairs to bed, the circumstances under which these are performed are variable. 


\section{Moving routines as sites for improvisation}

Our sample has shown some consistent patterns in the ways participants conducted their bedtime and morning routines (Pink and Leder Mackley 2013), but always with variations. For example, where the materiality of homes was made by participants leaving cables hanging out of sockets ready to re-charge their phone as they went through during established and habitual routes. TVs are switched off and checked during the bedtime routine, but there can be variation in relation to if TVs (even within the same household) are left on standby, on a timer or switched off at night (Pink and Leder Mackley 2013). Lighting was consistently used to make and navigate through atmospheres of night time homes, but the types of lighting used and borrowed and the ways this was done, were contingent on spatial, technological, social and biographical configurations. While one household might always leave night lights on, another participant showed us how she never puts a light on as she walks along the dark corridor to the light switch for downstairs.

Lighting, locking and media tended to figure in the bed time routines across the examples we have discussed. In this sense we found out what we expected. But, by following the participants, as we have shown through focusing in on the example of lighting here, we also found what we couldn't expect. It is impossible to anticipate how another person senses their night time home and through our video recorded reenactments we have focused on learning how our participants used light to create affective atmospheres of the night time home. These are the habitual things people do 'without thinking about them' when they are tired at bed time, that is, when doing what they usually do 'without really thinking about it'. Yet at the same time the routes and routines we followed were scattered with moments of improvisory neatness, where there were invisible 'logics' that participants had to explain to us. By this we mean that there were things that participants did, and that they tacitly knew, that we could not have understood had they not then described to us verbally the rationales that underpinned them. For example, the way that Alan borrowed the sensor-triggered light from outside to take his shoes off just in time before it switched off automatically, how he backtracked in order not to use direct light in the living room, or how Lee put his living room light on, 
on leaving the room with the cat, so that he would remember to return to the room; as Lee pointed out to Kerstin, there was a reason for this, and as Alan told Sarah, it was a matter of turning on the lights he needed. Both use lighting in ways that enabled them to know their environments in a particular way, and that made or maintained an appropriate atmosphere for and of the night time home. It is here that the making and experiencing of the environment of home can be said to converge through the concept of atmosphere and where we can see how lighting is implicated in this.

Seeing these activities as forms of making in movement therefore helps us to understand how people improvise as everyday designers. Improvisation is, as Ingold and Hallam (2007) emphasise, ongoing, and we do not claim that any of the idiosyncratic ways of doing things that our participants showed us and explained to us can be identified as a complete or completed improvisation, or to pinpoint specific instances of change. Instead, our argument is that a routine, part of a pathway of movement that is repeated daily, can be a significant site for improvisory activity. Our snapshots or representations of individual routines do not show improvisation happening in an explicit way, but rather they catch it at one moment in its processuality, as they cut through the ongoing temporality of everyday life. Just as we noted Böhme's point that making atmospheres makes possible 'the appearance of a phenomenon by establishing conditions' $(2013,4)$, improvisation in night time routines of movement does not make completed 'things' or products, but as we have seen, it makes the ongoingly shifting atmosphere of the night time home.

\section{Making atmospheres and making co-design}

The study of the use of light in the home has already led to some key observations about the culturally specific elements of everyday life it can bring to the fore. As Bille and Sørensen point out 'The way lightscapes are created by revealing people, spatiality and things, may reflect issues of moral principles, power, identity, sociality, and so on' (2007, 280). We would concur that amongst our participants uses of light at bed time could be situated within complexes of such forms of relationality such as caring for others, being quiet and more. Indeed studying how people use light leads us to interesting conclusions about how social relations and structures are made and maintained too. However we want 
to push further the question of what we can learn from studying how people use light in their homes, in that we are concerned not only with what it can tell us about what people already do, but with what it implies about the possible - that is how it enables us to imagine how the improvisory activity that is part of how light is used to make atmospheres of home might continue, beyond the past temporality of our project and beyond the now.

Above we have discussed the concept of routines and suggested conceptualizing the routine as a route, thus making movement through the home an inevitable quality of routines of home. This has enabled us to test the idea of the routine as a category through which to explore what people do in their homes. However rather than seeing the routine as a closed entity or analytical unit, we have understood in the same spirit that we have conceptualized the making of atmospheres. Thus routines are as they are lived, open ended but punctuated by moments of transition. They are part of a world in which, as Doreen Massey writes, 'we can't go "back”" (Massey 2005, 137). Everyday life is about movement forward - it has been characterised by scholars from various disciplines as being a 'flow' - something indeed that has also been regarded as a methodological challenge (Highmore 2002, Pink 2012). Our ethnography has alerted us to the idea that it is within these paths of movement that both known routine and mundane improvisation coincide and become merged as improvisory activity becomes tacitly known as an embodied way of being and incorporated into a routine. The routines we have studied are punctuated by the end of the evening - the getting up to walk through the home switching on and off lights on the way - and finally getting into bed to sleep. However none of these actions mean that anything 'stops' indeed, while there is no space to cover it in this article, the night time home is active in a number of ways.

Therefore we propose routines of movement are useful analytical constructs. They enabled us to delineate a set of activities in such a way that when we asked people to show us their going to bed routines they shared with us rather similar moments in their days. Yet, we stress, that our interest is not in the routine as an entity (abstraction) but in the routine of movement as an analytical device through which to encounter the embodied, sensory and unspoken encounters between people and things that produce affective atmospheres of home. Thus where Merriman proposes to 'position movement, 
rhythm, force, energy or affect as primitives or registers that may be of equal importance when understanding the unfolding of events' rather than 'approach[ing] space and time as privileged measures for conceptualising location, position and context' $(2011,24)$ we would agree. We do not regard routines of movement as 'things' that can be changed, or as measures, instead we regard them as the sites through which the possibilities for change might be opened up.

\section{Routines of movement as sites of the possible}

As scholars engaged in research that has applied as well as academic implications, we have a double responsibility. First we wish to produce research that represents the experiences of our participants as loyally as possible and that connects ethnographic experiences with theoretical development. Second in the context of the project discussed above we have the responsibility of using our ethnographic-theoretical knowledge to inform the making of digital design interventions that will help our participants to reduce their energy demand.

We do not consider our task to be simply to inform designers with ethnographic insights about what people do in their homes, which might then be used to inform ways of modelling either 'personas' to design for to the making of prototypes to be tested. Instead our aim is to build on our ethnographic and theoretical findings to suggest where and how co-design might happen. Theoretically, we have understood everyday life routines and routes as short stretches in the pathways of movement through which people live life. As they moved through everyday environments our participants used embodied tacit sensory ways of knowing to navigate familiar tangible and intangible areas. As they went, they were incrementally learning, knowing and improvising, in ways that would normally be unseen and that would also have been invisible to us had we not specifically sought to understand by asking participants to show us the kinds of everyday activities that they would not normally think it worth showing anyone. As our examples demonstrate this means that each individual might be thought to doing something similar to others, yet her or his pathway will be unique, as will the things she or he knows as she or he enacts everyday idiosyncratic forms of making, which incrementally become habitual. These routines are thus moments in movement where interventions are already 
being made by the participants themselves, which suggests that these routines are open to improvisation and to the making of change. This takes us back to the question posed by Ingold, where as we have mentioned above he asks how we might 'design for improvisation' (original italics), where 'the improvisory interventions of practitioners present an opportunity rather than threat' (Ingold 2012, 32).

Our research implies a response to that question, albeit in a specific context. Our proposal is that we should be taking seriously routines of movement and making through the home as the very sites at which co-design processes might be generated. Routines, such as those where night time atmospheres are made and maintained, habitually each night, are regular and almost inevitable in the culturally specific context where we researched. Moreover as routines of making atmospheres they have much in common with the proposals for phenomenologically inspired co-design practice by the designers Yoko Akama and Alison Prendiville, who call for a shift away from an approach to design that they critically assess as 'the object-centred legacy [which] still holds firm, and with it, its tools and offerings - touch-points, digital artefacts, blueprint, service concept map' to instead engage with 'the active power of the process of co-designing' (Akama and Prendiville 2013, 31). They reframe 'co-designing as a journey and process of transformation in how we design our world, and ourselves, with others' (Akama and Prendiville 2013, 31). Co-designing thus described is like making atmospheres - a process of making the unfinished. How then, might co-designing for energy demand reduction become part of the process of making affective atmospheres of home? We do not answer this question in full here; it is a question that requires a research process that would embed it in the specificity of the routines of movement, not simply a theoretical response. However we set out the more general implications.

Our sensory ethnography of energy and digital media set out to initially explore how our participants made and experienced the sensory aesthetic of their homes, how they sought to make their homes 'feel right', and how energy demand was implicated in this. As such we have interpreted what they were doing as making affective atmospheres of home. Everyday routines of movement, were identified through our research as moments where these processes of making atmospheres of home were particularly pertinent and obvious. Therefore if we, for the sake of simplifying the finding into an 
object that might be designed into, suggest that what people are seeking to do at night time, as well as in other times in their days, is to create atmospheres, then the objective of a co-design process would be to begin to participate in the making of affective atmospheres of home. To direct this process with participants to finding ways to make atmospheres with lower energy demands, and indeed to even make a sense of lower energy demand part of that atmosphere, a way of making the home 'feel right'. Here, we stress we are not referring to the idea of using less energy by reducing the use of lighting. Lighting is only a small part of the story and has been our vehicle through which to show how moving and making are central to the story of how everyday life is lived. However it is because lighting is so habitual and so (almost) inevitable in the UK context, that we have been able to pin our discussion on it. Therefore it might also be a form of making that co-design interventions could be pinned onto. The next stage, we propose is therefore to begin to explore in practice how co-design could become interwoven with routines of movement.

Here we suggest lies the opportunity and challenge both for the study of movement and for the designing of everyday routines; by engaging design as a collaborative activity that follows the pathways of movement of everyday life, rather than that seeks to make breaks in them. Routines cannot be redesigned, because they are not things that can be stopped, caught, changed and re-inserted into everyday life. Rather routines are forms of movement that themselves are already incrementally changemaking. Therefore our proposal is that movement has a new role to play as a key concept, and paradigm through which to approach co-design practice. This also means a closer coming together of mobilities research and design research.

\section{Acknowledgements}

The interdisciplinary LEEDR (Lower Effort Energy Demand Reduction) project, based at Loughborough University, is jointly funded by the UK Research Councils' Digital Economy and Energy programmes (grant number EP/I000267/1). For further information about the project, collaborating research groups and industrial partners, please visit www.leedr-project.co.uk. The authors would like to thank all the households who have generously participated in this research. In the context of this article, we are especially 
grateful to Alan and Lee.

\section{References}

Akama, Y. and A. Prendiville. 2013. 'Embodying, enacting and entangling design: a phenomenological view to co-designing services' Swedish Design Research Journal 1(13): 29-40

Anderson, B. 2009. 'Affective atmospheres', Emotion, Space and Society 2: 77-81.

Bille, M. and Sørensen, T. 2007. An anthropology of luminosity: the agency of light, Journal of Material Culture, 12(3): 263-284

Bille, M. 2014. 'Lighting up cosy atmospheres in Denmark', Emotion, Space and Society, http://dx.doi.org/10.1016/j.emospa.2013.12.008

Bissell, D. 2010. 'Passenger mobilities: affective atmospheres and the sociality of public transport', Environment and Planning D 28: 270 -289

Blunt, A. and R. Dowling 2006. Home. Abingdon: Routledge.

Böhme, G. 1993. 'Atmosphere as the fundamental concept of a new aesthetics'. Thesis Eleven 36: 113-126.

Böhme, G. 2013. The art of the stage set as a paradigm for an aesthetics of atmospheres, Ambiances: International Journal of Sensory Environment, Architecture and Urban Space [online] (published online 10 February 2013., http://ambiances.revues.org/315

Brickell, K. 2012. 'Mapping' and 'doing' critical geographies of home' Progress in Human Geography 36(2) 225-244

Casey, E. and L. Martens (eds) 2007. Gender and Consumption: Material Culture and the Commercialisation of Everyday Life, Ashgate Press,

Edensor. T. 2010. 'Walking in rhythms: place, regulation, style and the flow of experience', Visual Studies, 25:1, 69-79, DOI: 10.1080/14725861003606902

Edensor, T. 2013. 'The Gloomy City: Rethinking the Relationship between Light and Dark' Urban Studies published online, DOI: 10.1177/0042098013504009

Ehn, B. and O. Lofgren 2009. 'Routines, Made and Unmade' in E. Shove et al eds. Time, Consumption and Everyday Life: practice, materiality and culture, Oxford: Berg. Ferguson, H. 2010. 'Walks, Home Visits and Atmospheres: Risk and the Everyday 
Practices and Mobilities of Social Work and Child Protection' British Journal of Social Work, 40 (4): 1100-1117.doi: 10.1093/bjsw/bcq015

Geurts, K. L. 2003. Culture and the senses: Bodily ways of knowing in an African community. Berkeley, Los Angeles, London: University of California Press.

Halkier, B., T.Katz-Gerro, and L. Martens 2011. 'Applying practice theory to the study of consumption: Theoretical and methodological considerations'. Journal of Consumer Culture 11: 3-13.

Harris, M. 2007. 'Introduction: Ways of knowing'. In Ways of knowing: New approaches in the anthropology of experience and learning, ed. Mark Harris,. Oxford: Berghahn.

Highmore, B. 2002. Everyday Life and Cultural Theory, London: Routledge Howes, D. (ed.) 1991. The varieties of sensory experience: A sourcebook in the anthropology of the senses. Toronto, Buffalo, London: University of Toronto Press.

Howes, D. 2005. Empire of the sense: The sensual culture reader. Oxford. Berghahn.

Howes, D. and Constance C. 2014. Ways of Sensing: understanding the senses in society, Oxford: Routledge

Ingold, T. 2000. The perception of the environment. London: Routledge.

Ingold, T. 2008. Bindings against boundaries: entanglements of life in an open world. Environment and Planning A 40: 1796-1810

Ingold, T. 2011. Being Alive: essays on movement, knowledge and description, Oxford: Routledge.

Ingold, T. and E. Hallam 2007. Creativity and Cultural Improvisation, Oxford: Berg Kuijer, L. A. de Jong and D. van Wijk (2013) 'Practices as a Unit of Design: An Exploration of Theoretical Guidelines in a Study on Bathing' Transactions on Computer-Human Interaction 20(4). Article no. 21.

Martens, L. B. Halkier and S. Pink. 2013. 'Researching habits: advances in linguistic and embodied research practice' International Journal of Social Research Methodology, DOI: 10.1080/13645579.2014.853999

Massey, D. 2005. For space. London: Sage 
Merriman, P. 2011. 'Human geography without time-space' Transactions of the Institute of British Geographers 37: 13-27.

Miller, D. 2001. (ed) Home Possessions, Oxford: Berg

O’Dell, T. 2009. 'My Soul for a Seat: community and the routines of mobility' in E. Shove et al eds. Time, Consumption and Everyday Life: practice, materiality and culture, Oxford: Berg.

Pink, S. 2004. Home truths. Oxford: Berg

Pink, S. 2009. Doing sensory ethnography. London: Sage.

Pink, S. (2010) The future of sensory anthropology/the anthropology of the senses. Social Anthropology 18, no. 3: 331-40.

Pink, S. (2012). Situating everyday life: Practices and places. London: Sage.

Pink, S. and K. Leder Mackley. (2012). Video and a sense of the invisible: Approaching domestic energy consumption through the sensory home. Sociological Research Online 17, no. 1, http://www.socresonline.org.uk/17/1/3.html.

Stafford, B. M. 2006. Echo Objects: The Cognitive Work of Images, Chicago: University of Chicago Press.

Thrift, N.J. 2008. Non-representatinoal theory: space, politics, affect, London: Routledge 